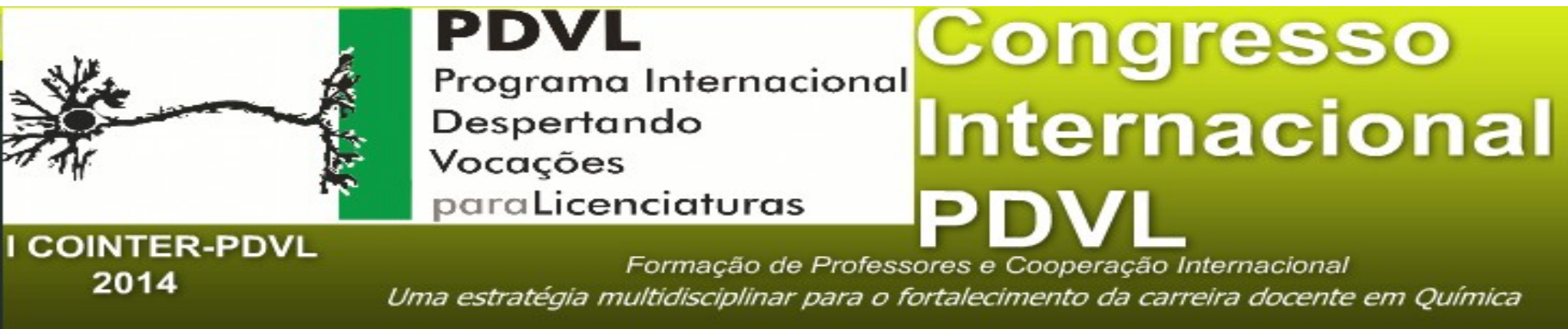

\title{
UM OLHAR DE ALUNOS DO ENSINO MÉDIO SOBRE A AVALIAÇÃO DA APRENDIZAGEM: investigando o Ensino da Química
}

Apresentação: Comunicação Oral

Rosivânia da Silva Andrade; Kilma da Silva Lima Viana²

\section{Resumo}

Ao passar dos séculos o ensino tem buscado formar não apenas cientistas, escritores, inventores, mas cidadãos, os quais possam pensar, refletir e agir perante o contexto que estão inseridos. Nesse contexto, a avaliação da aprendizagem se torna uma forte aliada nessa mudança, mas como os estudantes veem a avaliação no seu dia a dia escolar? Em resposta, a pesquisa buscou investigar as concepções de estudantes do Ensino Médio sobre a avaliação da aprendizagem. Com uma abordagem qualitativa, os sujeitos da pesquisa foram cinquenta e sete estudantes de uma Escola Estadual localizada no Município de Vitória de Santo Antão, Pernambuco das três séries do Ensino Médio. Após a análise dos dados, foi constatado que a maioria dos estudantes apresenta concepções de avaliação de Terceira e Quarta Geração, proporcionando a construção de seres dotados de saberes em prol de uma melhor convivência em sociedade. Os demais estudantes, em contrapartida, apresentaram concepções de Primeira e Segunda Geração da avaliação, o que vai de encontro às novas perspectivas para o Ensino da Química, que é formar estudantes, como também cidadãos críticos, autônomos e reflexivos perante o contexto sócio-científico-cultural. Portanto, as perspectivas da aprendizagem vão para além da forma tradicional de pensar o ensino-aprendizagem, com o intuito de superar a forma mecânica de aprender e de reproduzir conteúdos, para isso a avaliação não deve ser

\footnotetext{
${ }^{1}$ Licenciatura Plena em Química/ IFPE /Grupo de Estudos e Pesquisas em Ensino de Ciências/ rosivaniandrade@gmail.com

${ }^{2}$ Professora da Licenciatura em Química/IFPE / Grupo de Estudos e Pesquisas em Ensino de Ciências/ kilma.lima@vitoria.ifpe.edu.br
} 
considerada um apêndice, mas constituinte da prática pedagógica, em que o professor vivencie e utilize da avaliação para a melhoria do ensino dessa área do conhecimento.

Palavras-chave: educação básica, ensino da química, gerações da avaliação.

\section{Introdução}

O mundo atual, em sua extrema complexidade, não mais permite que o Ensino Médio seja apenas preparatório para um exame de seleção. Ele exige que o estudante se posicione, julgue e tome decisões, e seja responsabilizado por isso. Além disso, as novas perspectivas para o Ensino Médio diz que a Química deve ser valorizada, na qualidade de instrumento cultural essencial na educação humana, como meio coparticipante da interpretação do mundo e da ação responsável na realidade (BRASIL, 2006). Em contrapartida, o ensino de ciências, em particular o Ensino da Química, não está proporcionando o desenvolvimento crítico-social do estudante, por estar sendo desenvolvido de forma monótona e complexa, além de com uma visão linear e fragmentada de ensino.

Entretanto, para que ocorra mudança no Ensino da Química, as formas avaliativas vivenciadas nessa ciência também tem que mudar. Uma vez que, não é possível inovar o ensino se a sua avaliação se prendem aos moldes tradicionais, quantitativos e classificatórios. Desse modo e em concordância com Silva (2003, p.12) “o sentido pedagógico do ensino é garantir o espaço e os meios para a viabilização das aprendizagens”. Pois, "há muitas formas de pensar o mundo, de explicá-lo e torná-lo significativo” (Azevedo 2001, p.57).

Nesse sentido, a Avaliação se torna parte integrante do processo de formação do estudante, uma vez que possibilita diagnosticar possíveis espaços a serem superados, conferir os resultados alcançados considerando as competências a serem formadas e identificar mudanças de trajeto eventualmente necessárias.

Desse modo, no Ensino da Química, em particular, a avaliação não está desenvolvendo o estudante a um ser critico e autônomo para que possa reconhecer e compreender aspectos científicos, tecnológicos e culturais no contexto em que vive.

Diante disso, a pesquisa teve como objetivo investigar as concepções de estudantes do Ensino Médio sobre a avaliação da aprendizagem e a análise dos dados construídos teve como base teórica as Gerações da Avaliação propostas por Guba e Lincoln (1989). 


\section{Fundamentação Teórica}

As Gerações da Avaliação

De acordo com Guba e Lincoln (1989), a avaliação passou por um processo de evolução histórica, que eles dividiram em quatro Gerações: Geração da Medida (Primeira Geração), quando avaliação e medida se confundem, pois seus instrumentos apresentam caráter, essencialmente, quantitativos que buscam quantificar, classificar, selecionar e conseguir resultados exatos, objetivos.

A Geração da Descrição (Segunda Geração), que apresenta as características da geração anterior, mas traz os aspectos da descrição dos pontos fortes e fracos atingidos em relação aos objetivos de aprendizagem previamente estabelecidos pelo professor. Nessa geração, os papéis são bem definidos, pois o professor é o avaliador e o aluno o único avaliado. Essa avaliação é feito apenas no final do processo e que é desconsiderado. A preocupação se limita à verificação se o aluno é capaz ou não de reproduzir os conteúdos ensinados aos alunos em um instrumento padronizado.

A Geração de Juízo de Valor (Terceira Geração) rompe com o aspecto quantitativo das gerações anteriores, pois está preocupada com a compreensão do aluno, na forma em que o aluno está construindo o conhecimento, assim, os instrumentos avaliativos são construídos para identificar "pistas” de processos de construção. Por esse motivo, nessa geração, são aplicados diversos instrumentos avaliativos durante todo o processo e não apenas no final como nas gerações anteriores. E os resultados da avaliação servirão para uma tomada de decisão que buscarão os caminhos para a aprendizagem.

Finalmente a Geração da Negociação (Quarta Geração), proposta por Guba e Lincoln (1989) para romper com a questão de que apenas o professor pensa e elabora todo o processo. Nessa geração os estudantes são convidados a se auto avaliarem e avaliam a disciplina e o professor. Todos os atores do processo discutem os ganhos e as perdas e as necessidades. As palavras-chaves são: diálogo e autonomia. A característica de regulação e de juízo de valor da terceira Geração faz parte dessa Quarta Geração, porém, não apenas os professores pensam, os alunos são corresponsáveis pelo processo de ensino e de aprendizagem. 
Contudo, a aprendizagem no Ensino Química ainda está relacionada às primeiras gerações de avaliação, essas que dão ênfase a questões quantitativas. No entanto é preciso a quebra desses modelos tradicionais, nos dias atuais, já que as novas perspectivas do ensino de Ciências buscam formar um estudante pensante e participativo. Para isso, como a avaliação não é um apêndice, mas algo constituinte da prática pedagógica, é importante que o professor vivencie e utilize da avaliação para a melhoria do ensino dessa área do conhecimento.

\section{Avaliação no Ensino da Química}

A avaliação como parte do processo de ensino aprendizagem, deve considerar as múltiplas dimensões do ensino para cada área do conhecimento. Desse modo, o professor deve refletir sobre suas práticas pedagógicas oportunizando momentos de aprendizagem em que o aluno possa compreender a realidade em que vive.

No entanto, o Ensino da Química tem se prendido a abordagens tradicionais de ensino, em que o processo avaliativo ainda está fragmentado e desarticulado, centrado em currículos e concepções que não atendem mais as perspectivas para o Ensino da Química (ANDRADE, 2013).

Nesse sentido, o processo avaliativo no ensino de ciências, em particular o da Química, em concordância com Silva (2003) vem resultando em uma avalanche de cobranças de nomenclaturas e informações adquiridas pelo aluno, a partir de testes objetivos, ou tarefas teóricas, sem a análise do seu desenvolvimento em termos do raciocínio lógico, experimentação científica e curiosidade acerca dos fenômenos naturais.

Entretanto, os Parâmetros Curriculares para o Ensino Médio (1998), no que diz respeito ao Ensino da Química, sustenta que é imprópria a avaliação que só se realiza numa prova isolada, pois deve ser um processo contínuo que sirva a permanente orientação da prática docente. Além de ser, segundo Fernandes (2009)

[...]um processo desenvolvido por e para seres humanos que envolve valores morais e éticos, juízos de valor e questões de natureza sociocultural, psicológica e também política. (FERNANDES, 2009 p.64) 
Nesse contexto, a avaliação rompe com as barreiras quantitativas da avaliação, medir e classificar não é mais o objetivo central, pois o válido é compreender, analisar e refletir para que possa, a partir dos conhecimentos científicos vivenciados no chão da escola, conhecer e explorar o contexto sócio, econômico, tecnológico e cultural em que estão envolvidos no mundo atual.

Em concordância com Silva (2004):

O sentido da avaliação é compreender o que se passa na interação entre o ensino e a aprendizagem para uma intervenção consciente e melhorada do professor, refazendo seu planejamento e seu ensino e para que o aprendente tome como consciência também de sua trajetória de aprendizagem e possa criar suas próprias estratégias de aprendizagem. (SILVA, 2004, p. 60)

Desse modo, no Ensino da Química, a avaliação deve orientar o processo de ensino aprendizagem para proporcionar aprendizagens de significados aos estudantes, para que eles possam se tornar cidadãos críticos, autônomos e participativos.

\section{Metodologia}

Com uma abordagem qualitativa, a pesquisa buscou investigar as concepções de estudantes do Ensino Médio sobre a avaliação da aprendizagem.

O Campo de pesquisa abrangeu uma Escola Estadual localizada no Município de Vitória de Santo Antão, Pernambuco e gerenciada pela GRE Mata Centro-Vitoria. Os sujeitos envolvidos foram cinquenta e sente estudantes $(\mathrm{a}=57)$ das três séries do Ensino Médio.

Como instrumento investigativo, foi utilizado um questionário semiestruturado visando: (i) Identificar e classificar as concepções dos estudantes nas Gerações de Avaliação; e (ii) analisar suas concepções e suas relações com as novas perspectivas para o Ensino da Química.

Portanto, para o alcance dos objetivos as discussões dos resultados apresentados foram analisadas a partir das Gerações de Avaliação propostas por Guba e Lincoln (1989).

\section{Resultados e Discussão}


De acordo com os nossos dados, as concepções dos estudantes foram, em sua maioria $(a=44)$ relacionadas com a Avaliação de Terceira e Quarta Geração, em que (a=44) definem a avaliação como um momento no qual professor e estudantes discutem e avaliam sobre o desenvolvimento de um determinado conteúdo. E muitos $(\mathrm{a}=35)$ que a finalidade da avaliação é verificar se o aluno conseguiu construir a aprendizagem durante a aula. Portanto, para ampliarmos as nossas análises, questionamos: Se você fosse um professor como avaliaria seus estudantes? Apesar de algumas respostas anteriores terem apresentado indicativos de Quarta Geração, os estudantes apresentaram respostas, que podemos relacionar à Terceira Geração, conforme apresentado abaixo:

"Eu faria aulas práticas, questionário oral, mais seminários para que a 'prova' normal ficasse melhor para todos”. (Estudante 13)

“Avaliaria meus alunos nos pontos fracos e na dificuldade, para ele melhorar”. (Estudante 49)

"avaliaria de forma para eles aprenderem mais e mais" (Estudante 02)

"buscaria usar métodos para avaliar a aprendizagem de cada aluno, pois tem uns que são mais difíceis de compreender”. (Estudante 35)

"Na participação nas aulas e também nas avaliações observaria seu desenvolvimento”. (Aluno 19)

Nesse contexto, essa forma de Avaliação proporciona a construção de ambientes de formação de indivíduos aptos a encarar a complexa realidade que os espera e prontos para também formar com seus saberes outros seres, desencadeando, desta forma, um ciclo onde o objetivo maior é a construção de seres dotados de saberes em prol de uma melhor convivência em sociedade.

No entanto, os demais estudantes apresentaram concepções de Primeira e Segunda Geração (a=13) quando definem a avaliação como, sempre, uma prova que é realizada ao final do bimestre. Como também, quando a maioria $(\mathrm{a}=17)$ afirma que a finalidade da avaliação é verificar se o estudante reproduziu o que o professor transmitiu na aula. E os demais ( $a=5)$ definem que a finalidade da avaliação é descrever os pontos fortes e fracos sobre o desenvolvimento do conteúdo. Do mesmo modo, para ampliarmos as nossas análises, questionamos: Se você fosse um professor como avaliaria seus estudantes? Esses estudantes 
permaneceram com respostas relacionadas às primeiras gerações, conforme apresentado abaixo:

"Com trabalhos, com atividades valendo nota e no final do bimestre uma prova para avaliar como o aluno se desenvolveu”. (Estudante 30)

“provas e trabalhos também”. (Estudante 21)

“através de provas para saber se o aluno aprendeu” (Estudante 48)

Nesse sentido, os maiores desafios para a atualização pretendida no aprendizado de Ciências, no Ensino Médio, estão na formação adequada de professores, na elaboração de materiais instrucionais apropriados e até mesmo na modificação do posicionamento e da estrutura da própria escola, relativamente ao aprendizado individual e coletivo e a sua avaliação (BRASIL, 1998), pois os professores ainda são referência dos estudantes, quando se trata da questão acadêmica. Se o estudante passa a vida escolar sendo avaliado de acordo com as ideias da Primeira e Segunda Gerações, dificilmente terão concepções mais emergentes.

Salientamos a importância de pesquisas realizadas no chão da escola, pois a investigação do cotidiano se torna uma peça chave para desenvolvimento de ações educativas diferenciadas, pelo fato de buscar entender as complexas temáticas do contexto educacional para melhor atender as demandas curriculares e também as necessidades de aprendizagem do estudante. O planejamento didático será feito partindo das necessidades observadas nesse processo investigativo sendo possível a elaboração de ações didáticas que superem a complexa realidade presente no cotidiano educacional.

\section{Conclusões}

As práticas avaliativas apresentadas e discutidas no âmbito da pesquisa nos trazem reflexões sobre a formação que está sendo proporcionada aos estudantes e suas relações com as novas perspectivas para o Ensino e avaliação em Química. Dessa forma, é preciso que os estudantes tenham conhecimento de que a avaliação vai além de provas e trabalhos escritos e individuais. Desse modo, é indiscutível a reflexão-ação-reflexão das práticas pedagógicas pelos professores para que eles possam possibilitar uma aprendizagem de significados aos seus estudantes e para que, de fato, a educação cumpra seu papel de formar não apenas 
cientistas, mas cidadãos, que possam contribuir para o desenvolvimento do contexto em que está inserido.

\section{Referências}

ANDRADE, R. S. ; LIMA, K. S. . As formas de avaliação no ensino da química: um estudo com professores do ensino médio. In: 65 $5^{\mathrm{a}}$ Reunião Anual da SBPC, 2013, Recife. Reunião Anual da Sociedade Brasileira para o Progresso da Ciência, 2013. v. 65. ISSN: 2176-1221

AZEVEDO, Joanir Gomes. A tessitura do conhecimento em redes. In: ALVES, Nilda; OLIVEIRA, Inês Barbosa de (org.). Pesquisa no/do cotidiano das escolas sobre redes de saberes. Rio de Janeiro: DP\&A, 2001.

BRASIL, Parâmetros Curriculares Nacionais: ciências naturais. Secretaria de Educação Fundamental. Brasília: 1998.

Ministério da Educação, Secretaria de Educação Básica. Orientações curriculares para o ensino médio - Ciências da natureza, matemática e suas tecnologias. Brasília: Ministério da Educação, Secretaria de Educação Básica, 2006.

Fernandes, D. Para uma teoria da avaliação formativa. Revista Portuguesa de Educação, 2009, vol. 19, n. 2, P. 21-50. ISSN: 0871-9187.

GUBA, Ergon G.; LINCOLN, Yvonna S. Fourth generation evaluation. Newbury Park, London, New Delhi: Sage, 1989.

SILVA, Janssen F. Avaliação na perspectiva Formativa-Reguladora: Pressupostos Teóricos e Práticos. Porto Alegre: Mediação, 2004.

Janssen F. Práticas avaliativas e aprendizagens significativas: em diferentes áreas do currículo. Porto Alegre: Mediação, 2012. 